\title{
Fen Bilgisi Dersine Yönelik Okul Dıșı Öğrenme Ortamları Etkinliklerinin Geliştirilmesi Ve Öğrencilerin Bilimsel Süreç Becerilerine Etkisinin Değerlendirilmesi*
}

\author{
Developing Activities Of Out Of The School Learning Environments \\ For Science Classes, And Analysing Their Effects On Students' \\ Scientific Process Skills
}

DOI $=\underline{10.17556 / j e f .41328}$

$$
\text { Zehra ERTEN**, Güntay TAŞÇİ*** }
$$

Özet

Bu çalışmada; okul tabanlı alan gezisinin ortaokul öğrencilerinin bilimsel süreç becerileri ile ilgili kazanımlarına etkisinin araştırılması amaçlanmıştır. Araştırma, yarı deneysel bir çalışma olup statik grup karşılaştırmalı desende tasarlanmıştır. Çalışma grubunu Erzincan ilinde öğrenim gören 56 beşinci sınıf öğrencisi oluşturmaktadır. Araştırmada deney grubunda, okul dışı alan gezisi doğa alanı olarak bir hobi bahçesinde, istasyonlarda öğrenme tekniği ile, kontrol grubunda ise mevcut öğretim programına uygun olarak sınıf ortamında öğretim yürütülmüştür. Elde edilen verilerin değerlendirilmesi için bir puanlama rubriği geliştirilmiştir. $\mathrm{Bu}$ pauanların ortalaması alınarak sonuçlar bağımsız gruplar t testi ile analiz edilmiştir. Araştırma sonucunda, okul dışı öğrenme ortamlarının, bilimsel süreç becerilerini geliştirme açısından, özellikle gözlem ve operasyonel tanımlama becerileri bakımından katkı sağladı̆̆ı tespit edilmiştir.

Anahtar Kelimeler: Fen eğitimi, okul dışı öğrenme ortamı, bilimsel süreç becerileri

\section{Abstract}

In this study was aimed investigation of the effects of school based field trips on scientific process skills of secondary school students. The study is a quasiexperimental research, and it was designed thorough static-group comparison design. The study group of research is consisted 56 students, who are in 5th grades in Erzincan. In experimental group, the study was performed in hoby garden during learning at the stations. On the other hand, the study was conducted in the classroom

*Bu çalışma ilk yazara ait yüksek lisans tezi olarak çalışılmış ve Erzincan Üniversitesi Bilimsel Araştırma Projeleri Koordinatörlüğü tarafindan desteklenmiştir (Proje No: EGT-C-YLP120515-0135).

** Bilim Uzmanı, Milli Eğitim Bakanlığı, mavis19_86@hotmail.com

*** Yrd. Doç.Dr., Erzincan Üniversitesi, gtasci@erzincan.edu.tr 
according to teaching program in control group. The participants of experimental group was provided observation form and information sheets regarding learn objects in station. The end of this study was applied for data collection an observation task and interview form. A rubric form was investigated for assesment of participants' tasks. The obtained data were assesed the rubric by two different rater. Mean of raters' scors were used to analyse the data using independent simple t-test. As a result, the study have been found that out of school learning environment contribute to improve the scientific process skills, especially, in terms of defining operational skills and observation skills.

Keywords: Science education, out of school learning envioronment, scientific process skills

\section{Giriş}

Bilimin yaşamımızdaki yeri düşünüldügünde, zamanla ortaya çıkan değişimlere ayak uydurmada fen öğretiminin önemli bir yere sahip olduğu görülmektedir. Herkesin günlük seçimlerini yapmak için bilimsel bilgi kullanmaya, fen ve teknolojinin de içinde olduğu önemli konular hakkında tartışabilmeye ve gerçekleşen yenilikler ile akıllıca meşgul olabilmeye ihtiyacı vardır. $\mathrm{Bu}$ doğrultuda, Amerika'da yayımlanan Ulusal Fen Eğitimi Standartları (NRC,1996) son yirmi yıldaki fen eğitimi uygulamalarında yön belirleyici olmuştur. Ulusal fen eğitim standartları (NRC, 1996) kapsamında tanımlanan standartlardaki önemli kavramlar bilim okur yazarlığı, araştırma inceleme, bilimsel süreç becerileri (BSB) ve toplum bilim teknoloji etkileşimi olarak sıralanabilir. $\mathrm{Bu}$ komisyonun farklı tarihlerde hazırladıkları raporlar incelendiğinde, Ulusal Fen Eğitimi standartlarının belirlenmesi ile başlayan süreçte okul dışı fen öğrenme ve informal öğrenme ortamları ile devam ettiği görülmektedir (NRC, 2012). Ülkemizdeki 2013 y1lında yenilenen fen öğretim programında ise, araştırma-sorgulama sürecinde yapılacak olan etkinliklerin daha çok sınıf ortamında yapılacak tarzda tasarlanması ancak imkânlar dâhilinde informal öğrenme ortamları ve laboratuvar olanaklarından da faydalanılabileceğini belirtmiştir (MEB, 2013).

Genel olarak öğrenme kavramının, dış koşullarını ifade eden öğrenme ortamı, özellikle öğretim materyallerinin ve görevlerinin yapılandırıldığı böylece istenen öğretim sürecinin gerçekleştirildiği alanlar olarak tanımlanmaktadır (Taşçı ve Soran 2008). Bilim ve 
teknoloji alanında gerçekleşen hızlı değişim birçok kavramda olduğu gibi öğrenme ortamı terimini de farklı yönleri ile genişletmiştir. $\mathrm{Bu}$ kapsamda öncelikle okul ve sınıf içi olarak düşünülen öğrenme ortamları, okul dişı ortamları da içerecek şekilde genişletilmiştir. $\mathrm{Bu}$ bağlamda literatürde öncelikle formal, informal öğrenme kavramlarının tartışıldığı, çeşitli alanların kavramsallaştırılarak sınıflanmaya çalışıldığı görülmektedir. Ancak, Hofstein ve Rosenfeld (1996) informal fen öğrenmenin tanımına ilişkin ortak bir kabul olmadığını bildirmektedir. Araştırmacılar buradaki temel problemin informal fen öğrenmeyi tanımlamada uygulama alanın formal düzenlemeleri içerip içermeyeceği olduğunu bildirmektedir. $\mathrm{Bu}$ çerçevede NRC (2009) öğrenme ortamlarını üç temel ölçüte bağlı özelliklere göre derecelendirmektedir. Bunlar kullanılan değerlendirme tipi, seçme derecesi ve tasarım (plan) olarak verilmektedir. $\mathrm{Bu}$ raporda fen öğrenme için okula bağlı düzenlemeleri içermeyen potansiyel fen ögrenme alanları informal öğrenme ortamları olarak ele alınmaktadır. Hofstein ve Rosenfeld (1996) tanımlanmasını zor gördüğ̈ informal fen öğrenme ortamlarının alan olarak müzeler, hayvanat bahçeleri, botanik bahçeleri, bilim merkezleri, doğa alanları gibi birçok çevrenin sayılabileceğini belirtmektedir. Bunun yanında Eschenhagen, Katmann ve Rodi (2008) okul bahçelerinden, tarım alanlarından, doğa koruma (milli park) alanları gibi okul yakınındaki tüm doğa alanlarının okul dışı öğrenme ortamı (ODÖO) olarak kullanılabileceğini belirtmektedir. Sturm ve Bogner (2010) müze, botanik bahçeleri, hayvanat bahçeleri, park, bahçe tarzında çeşitli doğa alanlarını okul dışı fen öğrenme kapsamında alan gezileri olarak nitelemektedir. Hofstein ve Rosenfeld (1996) tarafindan formal düzenlemeler içeren zorunlu okul dişı öğrenme etkinlikleri informal fen öğrenmenin hibrit tanımı olarak kabul edilmektedir. Bu kapsamda okul temelli alan gezileri, doğrudan gözlemlenebilecek, incelenebilecek öğretim materyallerinin olduğu bir yere öğrenciler ile eğitim amaçlı olarak okul tarafından düzenlenen geziler olarak tanımlanmaktadır. $\mathrm{Bu}$ ortamlar geleneksel ortamlara nazaran daha açık, demokratik, esnek ve öğrenci merkezli öğretim özellikleri olan ortamlar olarak görülmektedir. Behrent ve Franklin (2014) alan gezilerini, eğitim amaçlı sınıf dışındaki öğrenci deneyimleri olarak ele almaktadır. Alan gezileri otantik ortamlarda deneyimler yolu ile bilim kavramlarının öğrenilmesini sağlamaktadır. 
$\mathrm{Bu}$ deneyimlerin kalitesi öğrenenlerin derinlemesine öğrenmelerini ve ilgilerinin artmasını sağlamaktadır. Yapılan birçok araştırma; ODÖO' larının öğrencilerin fen becerilerinin gelişmesinde, çeşitli bilimsel konuları keşfederek öğrenmesinde, akademik başarılarının ve fene karşı tutumlarının artmasında ve bilimsel meraklarının canlanmasında etkili olduğu ve öğrenmeyi kolaylaştırdığı, birinci elden deneyim kazanılmasına firsat verdiği, gerçek yaşam ile okulda öğrendikleri arasında ilișki kurma, gözlem yapma, veri toplama ve sonuca ulaşarak yorum yapma becerilerinin gelişmesine katkı sağladığını göstermektedir (Balkan Kiyıcı ve Atabek Yiğit, 2010; Bozdoğan, 2007; Chin, 2004; Cox-Petersen, 1999; Griffin, 2004; Guisasola, Morentin ve Zuza, 2005). Bu faydaların yanı sıra, ODÖO' ları formal eğitimi desteklemesi (Gerber, Cavallo \& Marek, 2001; Hannu, 1993), programın hedeflerini kazandirması (Ramey-Gassert, 1997; Yavuz ve Kıyıc1, 2012; Yılmaz, 1996) ve çevre bilinci oluşturması (Berberoğlu \& Uygun, 2013; De White ve Jacobson, 1994; Güler, 2009) yönünden de literatürde önemli bir yer tutmaktadır. $\mathrm{Bu}$ bağlamda, öğrencinin BSB' ni kullanıp bilgiyi yapılandırmasına, fen bilimleri dersi kapsamında yer alan ünitelerdeki kavramları somutlaştırmaya, ilk elden kaynak sağlamaya en uygun öğrenme ortamları da okul dışı öğrenme ortamlarıdır.

$\mathrm{Bu}$ araştırmanın amacı fen ve teknoloji dersinde ODÖO' larının kullanılmasına ilişkin etkinlikler geliştirilmesi ve bunların öğrencilerin BSB bakımından değerlendirilmesidir. Okul dışı fen öğrenmenin genel çerçevesi doğadaki olgular hakkında bilgi kazanmak için bilime karşı heyecan, ilgi, içsel güdülenme oluşturma, bilimsel kavramlar ile ilgili model, anlam, açıklama, yansıma üretme, bunlar için doğadaki olguları gözlem, inceleme yoluyla araştırma, bilimsel etkinliklere katılmayı sağlama olarak belirlenmiştir (NRC, 2009). Buna göre fen ögretim programındaki kazanımların öğrenenlere okul koridorlarının ötesinde, okul dışındaki çok çeşitli bilim öğrenme firsatlarının olduğu alanlarda bilim ile ilgili açıklamaları, keşifleri, olguları deneyimleyerek gerçekleştirilmesi önemlidir. Böylece, öğretmenlerimizin etkinlikler planlama ve uygulama yolu ile bu sürece katılmaları ve öğrencilerin güncel hedeflere uygun eğitim 
almaları için katkı sağlanmış olacaktır. Bu bağlamda araştırmanın temel problemi aşağıdaki gibi oluşturulmuştur:

Fen ve Teknoloji dersinin okul dışı öğrenme ortamlarındaki etkinliklere göre düzenlenmesi, öğrencilerin BSB' nde fark oluşturmakta midır?

$\mathrm{Bu}$ probleme çözüm oluşturmak için; şu alt probleme cevap aranmıştır.

Okul dışı öğrenme ortamlarında etkinliklerin yürütüldüğü deney grubu ile sınıf ortamında öğretim alan kontrol grubunun BSB' ne ilişkin puanları arasında istatiksel olarak anlamlı bir farklılık var midir?

\section{Yöntem}

$\mathrm{Bu}$ bölümde; araştırmanın modeli, çalışma grubu, veri toplama araçları, veri toplama araçlarının uygulanması son olarak ise; verilerin toplanması ve analizine ilişkin bilgiler yer almaktadır.

\section{Araştırmanın Modeli}

Araştırma, yarı deneysel bir çalışmadır. Çalışma statik grup karşılaştırmalı desende tasarlanmıştır. Bu deneysel süreç şekilde gösterilmiştir (Büyüköztürk, Çakmak, Akgün, Karadeniz ve Demirel, 2013, s. 202).

Tablo 1. Araştırma Deseni (Son test denkleştirilmemiş gruplu desen)

\begin{tabular}{lll}
\hline Grup & İşlem & Son test \\
\hline Deney & Okul dişı öğrenme ortamındaki & Bilimsel süreç becerileri \\
Grubu & etkinlikler & görevleri \\
Kontrol & Mevcut programa uygun sınıf içi & Bilimsel süreç becerileri \\
Grubu & öğretmen merkezli öğretim & görevleri \\
\hline
\end{tabular}

Öğrencilere, öğretim programında öngörülen sürelerde eşit ders yapılmıştır. Deney grubunda sadece gezi öncesi uyarılar ve gezi sonrası dönütler sınıf ortamında verilmiș, uygulamalar alan gezisindeki istasyonlarda gerçekleştirilmiştir. 


\section{Çalışma Grubu}

Araştırmanın çalışma grubunu 2014-2015 eğitim- öğretim y1lında Erzincan İl'inin İliç İlçesi'nde bulunan bir orta okulda öğrenim gören 56 beşinci sınıf öğrencisi oluşturmaktadır. Bu öğrencilerin 29'u deney grubunda, 27'si kontrol grubunda yer almaktadır. Çalışma grubu seçiminde seçkisiz örnekleme yöntemlerinden basit seçkisiz örnekleme yöntemi kullanılmıştır.

Tablo 2. Çalışma Grubunda Yer Alan Öğrencilerin Cinsiyetlerine Göre Dağılımı

\begin{tabular}{llll}
\hline Grup & Cinsiyet & Frekans (f) & Yüzde (\%) \\
\hline Deney Grubu & Kiz & 12 & 41,38 \\
& Erkek & 17 & 58,62 \\
Kontrol Grubu & Kiz & 11 & 40,74 \\
& Erkek & 16 & 59,26 \\
\multirow{2}{*}{ Toplam } & Kiz & 23 & 41,07 \\
& Erkek & 33 & 58,93 \\
\hline
\end{tabular}

Tablo 2' deki verilere göre; araştırmanın çalışma grubunun \%41,07' si kız, \%58,93' ü de erkek öğrencilerden oluşmaktadır. Buna ek olarak; çalışma grubunu \% 14,29' unun 10 yaş, \% 80,35' inin 11 yaş ve \% 5,36' sinın da 12 yaş öğrenciler oluşturmaktadır. Ayrıca çalışma grubunun \% 60,71' inin ilçede, \% 39,29' unun da köyde ikamet ettiği, anne ve baba eğitim durumun ise yaklaşık \% 50' sinin ilkokul olduğu elde edilen verilerde görülmektedir. Önceki yıllarda ODÖO' larındaki faaliyetlere katılan öğrenci oranı \% 16,07 iken katılmayan öğrenciler ise çalışma grubunun \% 83,93' nü oluşturmaktadır.

\section{Veri Toplama Aracı}

$\mathrm{Bu}$ araştırmada gözlem, veri kayıt etme, ölçme ve sınıflama ve operasyonel tanımlama becerilerini gerektiren gözlem formları ile veri toplanmıştır. 


\section{Gözlem formu}

İki çalışma grubu arasındaki farkı görmek için üç bitki (Çam, Sedir, Elma) belirlenmiş ve özellikleri araştırılmıştır. Bu özellikleri incelemeye ve yorumlayabilmeye yönelik açık uçlu sorular geliştirilmiştir. Bu sorular ile taslak gözlem formu oluşturulmuştur. Üç alan uzmanının görüşü alınarak görüşme sırasında uygulanacak 3 adet soru içeren gözlem formu geliştirilmiştir. Sorularda üç bitkinin yaprağı ve tohumuyla ilgili özelliklere yer verilmiştir. Son olarak bitkilerin karşılaştırılmasına yönelik açık uçlu sorular sorulmuştur. Gerekli araştırmalar yapılarak bu gözlem formunda bulunan bitkilerin yaprağı, meyvesi, gövdesi ve familyası ile ilgili özellikleri içeren bilgi yaprakları oluşturulmuştur.

\section{Uygulama ve Veri Toplama Süreci}

Araştırma problemine çözüm üretmek için, kontrol grubuna müfredata uygun olarak, sınıf ortamında, tahta ders kitabı ve görseller kullanılarak öğretmen merkezli bir öğretim gerçekleştirilmiştir. Deney grubuna ise aynı ünite kapsamındaki konular müfredatta öngörülen sürelere uygun olarak eşit ders saati içerecek şekilde okul yakınındaki bir meyve bahçesinde işlenmiştir. Bunun için önceden oluşturulan üç gruptan her bir grup bir istasyona yerleştirilmiştir. Öğrenciler bulundukları istasyondaki bitkileri incelemiş ve bilgi yapraklarını da kullanarak gözlem formlarını doldurmuşlardır. Daha sonra gruplar yer değiştirerek aynı işlemi diğer istasyonda da uygulamışlardır. Bu dönüşüm bütün öğrencilerin 3 istasyonda da çalışma yapması ile sona ermiştir. $\mathrm{Bu}$ uygulamalar bitirildikten sonra her iki gruptan da araştırma sorularının cevaplanması için veri toplanmıştır. Bunun için deney ve kontrol grubunda bulunan 56 öğrencinin yapılandırılan BSB görevleri ile ilgili gözlem formlarını doldurmaları sağlanmış ve yarı yapılandırılmış görüşme gerçekleştirilmiştir. Görüşme okul içindeki sinıflardan bir tanesinde öğrenciler ile tek tek gerçekleştirilmiştir. Hazırlanan görev kapsamında her öğrenci bitkileri inceleyip, bilgi yapraklarınıda kullanarak gözlem formlarını doldurmuştur. Gözlem uygulamasının ardından da her öğrenciyle ayrı ayrı yarı yapılandırılmış görüşme yürütülmüştür. Yürütülen görüşmeler ortalama 1 ila 3 dakika arasında sürmüş ve kayıt altına alınmıştır. 


\section{Veri Analizi}

Deney ve kontrol gruplarının rubrik puanlarının analizi İlişkisiz (Bağımsız) Örneklemler t-Testi ile yapılmıştır. Büyüköztürk’e (2011) göre; İlişkisiz (Bağımsız) Örneklem t-Testinin yürütülmesi için, aşağıdaki koşulların sağlaması gerekmektedir:

Bağımlı değişkene ait ölçümler aralık ya da oran ölçeğinde olmalidir.

Bağımlı değişkene ilişkin ölçümler her iki grupta da normal dağılım göstermelidir. olmalidir.

Ortalama puanları karşılaştırılacak örneklemler ilişkisiz

İlişkisiz ya da bağımsızdan kasıt şudur: Ortalama puanları karşılaştırılacak veriler farklı gruplardan alınmış olmalıdır. Örneklem grubu evrenden rastgele seçilmiş olmalı ve her bir veri diğerinden bağımsız olmalıdır. Bu çalışmada, deney ve kontrol grubu verilerinin birbirini etkilemediği görülmüştür. Çalışmada rubrik değerlendirmesindeki puanlar eşit aralıklı ölçekte elde edilmiştir. Deney ve kontrol grubunda dağglımların normal dağılım gösterip göstermediğinin sorgulanması adına öncelikle çarpıklık ve basıklık katsayıları incelenmiş ve normal dağılım olduğu görülmüştür. İstatistiksel analizler yürütülürken anlamlılık düzeyi 0,05 olarak alınmıştır. Bu analiz için SPSS 18.0.0 (Statistical Packet for Social Sciences) paket programından yararlanılmıştır.

\section{Verilerin değerlendirilmesi}

Analiz için, öğrencilerin bilimsel süreç becerileri ile ilgili verilerinin puanlanmasında rubrik kullanılmıştır. Öğrenci beceri ve kazanımları çok boyutlu ve değişim gösteren yapılardır. Bu nedenle, bu beceriler çoktan seçmeli test uygulamaları dışında farklı değerlendirme araç ve yöntemleriyle ölçülmelidir. $\mathrm{Bu}$ doğrultuda özellikle 1990 yılından bu yana öğrenci merkezli eğitim anlayışı önem kazanmış ve çeşitli ölçme ve değerlendirme yöntem (performans değerlendirme, portfolyo değerlendirme, vb.) ve araçları (rubrik, kontrol listeleri, tutum ölçekleri, puanlama yönergeleri, vb.) kullanılmaya başlanmıştır Rubrik, öğrenci performansının süreçle 
birlikte farklı boyutlarda değerlendirilmesidir (Sezer, 2005). Bu araştırmada bilimsel süreç becerilerini değerlendirmek için analitik puanlama anahtarı kullanılmıştır. $\mathrm{Bu}$ rubrikte, öğrencilerden sergilemeleri beklenen BSB kazanımları dört boyuta ayrılmış ve üç ayrı performans düzeyine ilişkin performans tanımları her dört görev için (Veri kayıt etme, ölçme sınıflama, operasyonel tanımlama, verileri ilişkilendirme) verilmiştir. Ayrıca, bu performanslara karşılık gelen puanlar da (0-1-2) gösterilmiştir. Rubrik iki farklı puanlayıcı tarafından puanlanmış ve analiz için bunların aritmetik ortalamaları kullanılmıştır. Puanların güvenirlikleri için ise iki puanlayıcı arasındaki tutarlılık hesaplanmıştır (Bkz.Tablo 3).

\section{Bulgular}

\section{Puanlayıcılar Arası Tutarlıklık}

İki farklı puanlayıcı tarafından dereceli puanlama anahtarıyla (rubrik) ayrı ayrı puanlanan aynı gözlem formu ve görüşme kayıtlarından elde edilen puanlar arasındaki ilişki Pearson Momentler Çarpımı Korelasyon Katsayısıyla hesaplanmıştır. Araştırmada puanlayıcılardan elde edilen değerlerin ortalaması kullanıldığı için Pearson ilişki kat sayısından Sperman - Brown güvenirlik tahmin formüllü ile güvenirlik katsayıları elde edilmiştir (Crocker ve Algina, 1986). Bu sonuçlar Tablo 3 'te verilmektedir.

Tablo 3 incelendiğinde korelasyon katsayılarının istatistiksel olarak anlamlı oldukları görülmektedir. Korelason katsayıları incelendiğinde ise puanlayıcılar arasında orta düzeyde ve aynı yönlü bir ilişki olduğu görülmektedir. İlişki katsayıları kullanılarak ulaşılan Spearman - Brown güvenirlik tahminlerinin kabul edilebilir düzeyde oldukları görülmektedir. 
Tablo 3. Puanlayıcılara Ait Betimsel İstatistikler, Pearson Korelasyon Katsayıları Ve Güvenilirlik Tahminleri

\begin{tabular}{llllll}
\hline Puanlayicılar & $\begin{array}{l}\text { Aritmetik } \\
\text { Ortalama }\end{array}$ & $\begin{array}{l}\text { Standart } \\
\text { Sapma }\end{array}$ & $\mathbf{n}$ & $\mathbf{r}$ & Güvenirlik \\
\hline PuanlayiciG1_1 & 1,143 & 0,86189 & 56 & $0,529^{*}$ & 0,70 \\
PuanlayiciG1_2 & 1,5 & 0,50469 & 54 & & \\
PuanlayiciG2_1 & 1,196 & 0,81842 & 56 & $0,576^{*}$ & 0,73 \\
PuanlayiciG2_2 & 1,037 & 0,51259 & 54 & & \\
PuanlayiciG3_1 & 0,786 & 0,73148 & 56 & $0,524^{*}$ & 0,69 \\
PuanlayiciG3_2 & 1,185 & 0,58516 & 54 & & \\
PuanlayiciG4_1 & 1,125 & 0,87516 & 56 & $0,692^{*}$ & 0,82 \\
PuanlayiciG4_2 & 1,071 & 0,73502 & 56 & & \\
\hline & & & & &
\end{tabular}

$*: \mathrm{p}<.05$

Buna göre araştırmada toplanan verilerin puanlamasında iki puanlayıcı arasında yeterli tutarlık olduğu görülmektedir. Bu durum yapılan ölçme işleminin güvenilir olduğuna işaret etmektedir.

\section{Bă̆ımsız Gruplar t Testi Sonuçları}

Tablo 4'deki analiz sonuçlarına göre; deney ve kontrol grubundaki öğrencilerin gözlem becerisini ölçen rubrik değerlendirme puanları ortalamaları arasında istatistiksel olarak anlamlı bir fark $(\mathrm{t}(54)=$ $3,414, p<0.05)$ olduğu görülmektedir.

Tablo 4. Gözlem Ve Model Oluşturma Becerisi Rubrik Puanları Ortalamalarına İlişkin Bağımsız Örneklem t- Testi Sonuçları

\begin{tabular}{lcccccc}
\hline Grup & $\mathbf{n}$ & $\bar{X}$ & SS & Sd & $\mathbf{t}$ & $\mathbf{p}$ \\
\hline Kontrol & 27 & 1,019 & 0,612 & & & \\
& & & & 54 & $-3,414$ &, 001 \\
Deney & 29 & 1,552 & 0,557 & & & \\
\hline
\end{tabular}

$\mathrm{Bu}$ durum ODÖO'larında uygulanan etkinliklerin gözlem becerisi üzerinde anlamlı bir etkisinin olduğunu göstermektedir. 
Tablo 5. Veri Kaydetme Becerisi Rubrik Puanları Ortalamalarına İlişkin Bağımsız Örneklem t- Testi Sonuçları

\begin{tabular}{lcccccc}
\hline Grup & $\mathbf{n}$ & $\bar{X}$ & SS & Sd & t & p \\
\hline Kontrol & 27 & 1,037 & 0,619 & 54 &,- 717 &, 477 \\
Deney & 29 & 1,555 & 0,614 & & & \\
\hline
\end{tabular}

Tablo 5'deki analiz sonuçlarına göre; ODÖO'nda etkinlikler uygulanarak ders işleyen deney grubu öğrencilerinin rubrik değerlendirme puan ortalaması $(X=1,037)$ ile, sınıf içinde ders işleyen kontrol grubu öğrencilerinin rubrik değerlendirme puan ortalamas1 $(X=1,555)$ arasında istatiksel olarak anlamlı bir farklılık görülmemiştir $(\mathrm{t}(54)=-, 717, \mathrm{p}>0.05)$. Bu durum ODÖO' larında uygulanan etkinliklerin veri kaydetme becerisi üzerinde anlamlı bir etkisinin olmadığını göstermektedir.

Tablo 6. Ölçme Ve Sınıflama Becerisi Rubrik Puanları Ortalamalarına İlişkin Bağımsız Örneklem t- Testi Sonuçları

\begin{tabular}{lcccccc}
\hline Grup & $\mathbf{n}$ & $\bar{X}$ & SS & Sd & t & p \\
\hline Kontrol & 27 & 0,907 & 0,605 & & & \\
Deney & 29 & 1,017 & 0,590 & &,- 688 &, 495 \\
\hline
\end{tabular}

Tablo 6'daki analiz sonuçlarına göre; ODÖO'nda etkinlikler uygulanarak ders işleyen deney grubu öğrencilerinin rubrik değerlendirme puan ortalaması $(X=1,017)$ ile, sınıf içinde ders işleyen kontrol grubu öğrencilerinin rubrik değerlendirme puan ortalaması $(\mathrm{X}=0,907)$ arasında istatiksel olarak anlamlı bir farklılık görülmemiştir $(\mathrm{t}(54)=-, 688, \quad \mathrm{p}>0.05) . \quad \mathrm{Bu}$ durum ODÖO'larında uygulanan etkinliklerin ölçme ve sınıflama becerisi üzerinde anlamlı bir etkisinin olmadığını göstermektedir.

Tablo 7'deki analiz sonuçlarına göre; ODÖO'nda etkinlikler uygulanarak ders işleyen deney grubu öğrencilerinin rubrik değerlendirme puan ortalaması $(X=1,345)$ ile, sınıf içinde ders işleyen kontrol grubu öğrencilerinin rubrik değerlendirme puan ortalamas1 
$(\mathrm{X}=0,833)$ arasında istatiksel olarak anlamlı bir fark oluştuğu $(\mathrm{t}(54)=$ $2,728, \quad \mathrm{p}<0.05)$ ve bu farkın deney grubu lehine olduğu anlaşı1maktadır.

Tablo 7. Operasyonel Tanımlama Ve Yordama Becerisi Rubrik Puanları Ortalamalarına İlişkin Bağımsız Örneklem t- Testi Sonuçları

\begin{tabular}{lrccccc}
\hline Grup & $\mathbf{n}$ & $\bar{X}$ & $\mathbf{S S}$ & Sd & $\mathbf{t}$ & $\mathbf{p}$ \\
\hline Kontrol & 27 & 0,833 & 0,679 & & & \\
Deney & 29 & 1,345 & 0,721 & & & \\
\hline
\end{tabular}

\section{Sonuç ve Tartışma}

Okul dışı alan gezisi etkinliklerinin ortaokul öğrencilerinin "Canlıları Tanıyalım" konusu dahilinde BSB'ne etkisinin incelendiği bu araştırmada; deney ve kontrol grubunun son test aritmetik ortalamaları hesaplanmıştır. Ortalamalar kıyaslandığında ODÖO'nda etkinliklerin yürütüldüğ̈̈ deney grubundaki öğrencilerin BSB düzeyinin, kontrol grubundaki öğrencilerin BSB düzeyinden daha yüksek olduğu görülmüştür. $\mathrm{Bu}$ araştırmada $\mathrm{BSB}$ ayrı ayrı performanslar olarak değerlendirilmiştir. Çalışkan ve Kaptan (2012), ilköğretim öğrencilerinde BSB performans değerlendirme ile kalıcı hale geldiğini ifade etmektedir.

Deney grubu öğrencilerinin okul dışı etkinliklere katılmasının, gözlem, veri kullanma ve model oluşturma becerisini olumlu yönde geliştirdiği görülmüştür $(\mathrm{t}(54)=-3,414, \mathrm{p}<0.05)$. Bu çalışmanın bulgularına paralel olarak Balkan Kıyıcı ve Atabek Yiğit (2010) çalışmalarında okul dışı ortamların gözlem yapmaya olanak sağladığını bulmuşlardır. Gruplar arasında veri kaydetme becerisi $(\mathrm{t}(54)=-, 717, \mathrm{p}>0.05)$ ile ölçme ve sinıflama becerilerine $(\mathrm{t}(54)=$ ,688, $\mathrm{p}>0,05)$ yönelik istatistiksel olarak anlamlı fark oluşmamaktadır. Veri kayıt etme, sınıflama etkinlikleri öğretim programı kapsamında sınıf içi uygulamalarda da yapılması bunun nedeni olarak düşünülmektedir. $\mathrm{Bu}$ araştırma da verilen gözlem formunda bu görevler bakımından öğrencilerin biribirlerine yakın durumlarda olmaları bu bulgu ile uyumlu görünmektedir. Bunların yanı sıra; 
deney grubu öğrencilerinin okul dışı etkinliklere katılmasının, operasyonel tanımlama ve yordama becerilerini olumlu yönde geliştirdiği görülmüştür $(\mathrm{t}(54)=-2,728, \mathrm{p}<0,05)$. ODÖO' larında operasyonel tanımlama ve yordama becerilerinin olumlu yönde gelişme sebebi olarak kişinin bilgiye ulaşma sürecinde aktif olup bilgiyi kendi içinde yapılandırması görülmektedir. Bu çalışmanın bulgularına paralel olarak Yavuz ve Balkan Kiyıc1 (2012) çalışmalarında, okul dışı öğrenme ortamlarının birebir etkileşim ile soyut kavramların somutlaştırılarak anlamlandırıldığını belirtmiştir.

Sonuç olarak, okul dişı alan gezileri botanik parktan bilim merkezlerine bir çok alana düzenlenebileceği gibi okul yakınlarındaki uygun doğa alanlarına da gerçekleştirilebilir. Bu çalışmada seçilen tarımsal amaçlı olmayan bir hobi bahçesi, farklı bitki örnekleri üzerinden canlıların çeşitliliğinin gözlenmesi ve anlaşılması için tasarlanmıştır. Hazırlanan ortamda öğrencilerin hem gerçek bitki örneklerini gözlemlemeleyerek betimlemeleri sağlanırken hem de bilgi yaprakları aracılığ sağlanmıştır. $\mathrm{Bu}$ durum yakın çevrelerinde her an gördükleri canlı örneklerine daha bilimsel bir gözle tekrar bakmalarına ve doğayı anlamlandırmalarına önemli katkı sağlamaktadır. Buna bağlı olarakta müfredatın öngördüğü gözlem yapma, sınıflama, ölçme, verileri kaydetme, verileri kullanma ve model oluşturma gibi BSB' nin gelişmesini sağlamaktadır. Randler, Baumgartner, Eisele ve Kienzle (2007) bu bulgulara paralel olarak; formal eğitimde yürütülen eğitim ve öğretim faaliyetlerinin okul dişı öğrenme ortamlarıyla desteklenmesi ile mevcut öğrenmelerin pekiştirileceğini, öğrencilerin BSB'nin ve çeşitli duyuşsal özelliklerininde olumlu gelişeceğini belirtmişlerdir. Bu tür ODÖO' larının, hem sınıf içi eğitimi hem de öğrencilerin BSB' nin gelişmesini destekler nitelikte kullanılması için, literatürde belirtildiği gibi, gezilerin önceden bir amaç doğrultusunda planlanması ve tekrarlanması gerekmektedir (Bozdoğan, 2007; DeWitt ve Osborne, 2007). Okul dışı gezilerin tekrarlanmamasının sebebi olarak birçok literatür; ulaşım zorluğu, karmaşık ve yüksek maliyetli olmasını belirtirken (Osborne ve Dillon, 2007) , bazı çalışmalar ise planlanmasının zorluğu, zaman darlığı, gerekli izinlerin alınması, evrak işleri ve öğretmenlerin bu konudaki olumsuz 
düşüncelerini öne sürmüşlerdir (Bozdoğan, 2012; Griffin ve Symington, 1997; Orion ve Hofstein, 1994). Bu çalışma okul yakınında bulunan bir bahçe de yapıldığı için maliyet, ulaşım, karmaşıklık konusunda zorluk yaşanmamıştır. Ama çalışma müfredatta belirtilen ders süresi dahilinde yapıldığı için zaman sıkıntısı yaşanmış ve tekrar yapılamamıştır. Bunun yanı sıra eğitim ve öğretimin önemli bir parçası olan velilerin ODÖO' nı eğitim alanları olarak görmemesinden dolayı gerekli izinlerin alınmasında zorluk yaşanmıştır. Bozdoğan (2007), ailelerin ODÖO' na çocuklarıyla gitme oranın düşük olduğunu tespit etmiş, Yavuz (2012) ise velilerin ODÖO' na karşı oluşan algılarının değiştirilmesine yönelik önerilerde bulunmuştur. $\mathrm{Bu}$ çalışmada edinilen bulgular, bu tür zorluklara rağmen ODÖO' larının sınıf içi eğitim-öğretim faaliyetlerini destekleyen ve öğrencinin gelişimine katkı sağlayan alternatif öğrenme ortamları olduğunu göstermiştir. Buna göre Okul dış1 öğrenme ortamlarında yapılacak etkinlikler fen programları ile ilişkilendirilerek öğrencilerin çeşitli kazanımlar edinmelerine, konuları daha iyi anlamalarına ve kavramları somutlaştırmalarına yardımcı olur. ODÖO ile ilişkilendirilerek uygulanan beşinci sınıf fen programını içeren bu çalışma, öğrencilerin bu tür ortamlarda BSB geliştirmesini dayanak alarak, öğrencilerin araştıran, sorgulayan, bir sonuca ulaşabilen bireyler yani fen okuryazarı bireyler olarak yetişebileceğini göstermektir.

Araştırma sonuçlarına göre aşağıdaki öneriler sunulmaktadır: Araştırmada karşılaşılan sorunlardan biri zaman yetersizliği olarak belirtilmiştir. $\mathrm{Bu}$ sorunun çözümü için; eğitim ve öğretim programlarında ODÖO' nda uygulanabilecek konular belirlenerek ders süresini etkin kullanmaya yönelik örnek etkinlikler verilebilir. Okul dışı ögrenme ortalarının ziyaret edilmesinde ki zorlukları aşmada belediyeler gibi yerel imkanlar teşvik edilebilir. Öğretmenlerin hem öğretim sürecini hem de değerlendirme sürecini yeni yaklaşımlar ile düzenlemesi için destekler sunulabilir. Araştırmacılar tarafından hem bilimsel süreç becerileri hem de okul dışı öğrenme ortamlarının farklı faktörler üzerine etkisini gösteren daha kapsamlı çalışmalar yürütülebilir. 


\section{Kaynaklar}

Balkan Kıyıcı, F. \& Atabek Yiğit, E. (2010) Science education beyond the classroom:a field trip to wind power plant. International Online Journal of Educational Sciences , 2 (1), 225-243.

Behrendt M. \& Franklin T. (2014). A review of research on school field trips and their value in education. Int. J. Environ. Sci. Educ. 9, 235-245.

Berberoğlu, O. E. \& Uygun S. (2013). "Sınıf Dışı Eğitimin Dünyadaki ve Türkiye'deki Gelişiminin İncelenmesi”. Mersin Üniversitesi Ĕgitim Fakültesi Dergisi.9 (2), 32-42.

Bozdoğan, A.E. (2007). Bilim ve teknoloji müzelerinin fen öğretimindeki yeri ve önemi. Yayınlanmamış doktora tezi, Gazi Üniversitesi, Eğitim Bilimleri Enstitüsü Ankara.

Bozdoğan, A.E. \& Yalçın, N. (2006). Bilim merkezlerinin ilköğretim öğrencilerinin fene karşı ilgi düzeylerinin değişmesine ve akademik başarısına etkisi: Enerji parkl. Ege Ĕgitim Dergisi, 2(7), 95-114.

Büyüköztürk, Ş., (2011). Sosyal bilimler için veri analizi el kitabı (14. Baskı). Ankara: PegemA Yayıncilık.

Büyüköztürk, Ş., Çakmak, E. K., Akgün, Ö. E., Karadeniz, Ş. \& Demirel, F. (2013). Bilimsel araştırma yöntemleri (15. Bask1). Ankara: Pegem Akademi.

Chin,C-C.(2004). Museum Experience -A Resource For Science Teacher Education. International Journal of Science and Mathematics Education, 2:63-90

Cox-Petersen A.M.(1999). Dive into Research at the Aquarium. Science Activities, $36(3), 34-36$.

Crocker, L., \& Algina, J. (1986). Introduction to classical and modern test theory. Toronto: Holt, RineHart, and Winston, Inc.

Çalışkan, İ.Ö \& Kaptan F. (2012). Fen Öğretiminde Performans Değerlendirmenin Bilimsel Süreç Becerileri, Tutum ve Kalıcılık Açısından Yansımaları. Hacettepe Üniversitesi Eğitim Fakültesi Dergisi 43: 117-129

De White T.G. \& Jacobson, S.K. (1994). Evaluating conservation education programs at a South American zoo. The Journal of Environmental Education, 25(4), 18-22.

DeWitt, J. \& Osborne, J. (2007). Supporting teachers on science- focused school tripsi: Towards an integrated framework of theary end practice. International Journal of Science Education, 29 (6), 685-710.

Eschenhagen, D., Katmann, U. \& Rodi, D. (2008). Fachdidaktik biologie. (4th edition) Ed. Ulrich Kattman. Aulis Verlag Deubner. Koeln. 
Gerber, B.L., Marek, E.A., \& Cavallo, A.M.L. (2001). Development of an informal learning opportunities assay. International Journal of Science Education 23(6), 569-583.

Griffin, J. (2004). Research on Students and Museums: Looking More Closely at the Students in School Groups. Science Education, 88 (1), S59- S70.

Griffin, J. \& Symington, D. (1997). Moving from task-oriented to learning oriented strategies on school excursions to museums. Science Education 81: 763-779.

Guisasola,J., Morentin,M. \& Zuza, K.(2005).School visits to science museums and learning sciences:a complex relationship.Physics Education,40 (6) ,544-549.

Güler, T. (2009). Ekoloji Temelli Bir Çevre Eğitiminin Öğretmenlerin Çevre Eğitimine Karşı Görüşlerine Etkileri. Eğitim ve Bilim, 34, 146-151.

Hannu, S. (1993). Science centre education. Motivation and learning in informal education. Helsinki University Department of Teacher Education. Finland. (Unpublished Doctoral Dissertation).

Hofstein, A. \& Rosenfeld, S. (1996). Bridging the gap between formal and informal science learning. Studies in Science Education 28: 87-112.

MEB (2013). Talim ve Terbiye Kurulu Başkanlı̆̆l, ilköğretim fen bilimleri dersi (4, 5, 6, 7 ve 8. Sinıflar) ögretim programı. Ankara: MEB Yayınları.

NRC (National Research Council), (1996). National Science Education Standards. USA: National Academy Press.

NRC (National Research Council), (2009). Learning science in informal environments: People, places, and pursuits. Washington, DC: National Academies Press.

NRC (National Research Council), (2012). National Science Education Standards. USA: National Academy Press.

Orion, N. \& Hofstein, A. (1994). Factors that influence learning during a scientific field trip in a natural environment. Journal of Research in Science Teaching 31(10): 1097-1119.

Osborne, J. \& Dillon, J. (2007).Research on learning in informal contexts:Advancing the field. International Journal of Science Education, 29 (12), 1441-1445.

Ramey-Gassert, L. (1997). Learning science beyond the classroom. The Elementary School Journal, 4, 433-450.

Randler, C., Baumgartner, S., Eisele, H., \& Kienzle, W. (2007). Learning at workstations in the zoo: A controlled evaluation of cognitive and affective outcomes. Visitor Studies, 10(2), 205-216. 
Sezer, S. (2005). Öğrencilerin akademik başarısının belirlenmesinde tamamlayıcı değerlendirme aracı olarak rubrik kullanımı üzerine bir araştırma. Pamukkale Üniversitesi Ĕgitim Fakültesi Dergisi, 18, 61-69.

Sturm, H. \& Bogner, F. X. (2010). Learning at Workstations in Two Different Environments : A Museum and A Classroom. Studies in Educational Evaluation $36,14-19$.

Taşç1, G. \& Soran, H. (2008). Hücre Bölünmesi Konusunda Çoklu Ortam Uygulamalarının Kavrama ve Uygulama Düzeyinde Öğrenme Başarısına Etkisi, Hacettepe Üniversitesi Ĕgitim Fakültesi Dergisi, 34: 233 - 243

Yavuz, M. (2012). Fen eğitiminde hayvanat bahçelerinin kullanımının akademik başart ve kayglya etkisi ve öğretmen-öğrenci görüşleri. Yayınlanmamış Yüksek lisans tezi, Sakarya Üniversitesi, Eğitim Bilimler Enstitüsü, Sakarya.

Yavuz, M. \& Balkan Kıyıcı, F. (2012). İnformal öğrenme ortamlarının ilköğretim öğrencilerinin fene karşı kaygı düzeylerinin değişmesine ve akademik başarılarına etkisi: Hayvanat bahçesi örneği. X. Ulusal Fen Bilimleri ve Matematik Eğitimi Kongresi Özet Kitabl. Niğde Üniversitesi Eğitim Fakültesi, Niğde.

Yılmaz, A. (1996). Müzelerde çocuk eğitiminin müze koleksiyonları bağlamında değerlendirilmesi ve Rahmi M. Koç sanayi müzesi örneğinde irdelenmesi. Yayınlanmamış yüksek lisans tezi, Yıldız Teknik Üniversitesi, Sosyal Bilimler Enstitüsü, İstanbul. 


\section{Extended Summary}

\section{Introduction}

Learning environment, which generally expresses the external conditions of the concept of learning, is defined as the domains in which especially teaching materials and teaching tasks are structured and thus the desired process of teaching is performed (Taşç1 and Soran, 2008). Rapid changes occurring in the field of science and technology have expanded the term of learning environment - just as it has expanded several concepts. Learning environments primarily thought as inside the classroom has been expanded in a manner as to include out of the school environments also. Yet, it is observed that the concepts of formal and informal learning are disputed in the literature, that efforts are made to conceptualise and classify various fields, and that there is no agreement on this concept. Hofstein and Rosenfeld (1996) point out that informal science learning environments -which they find difficult to define- can be listed as museums, zoos, botanical gardens, science centres and fields of nature. Besides, Eschenhagen, Katmann and Rodi (2008) state that all fields of nature such as school gardens, agricultural fields, and national parks close to schools can be used as out of the school learning environments. Behrent and Franklin (2014) consider trips to these fields as students' educational experiences out of the school. Field trips ensure that the concepts of science are learnt in authentic environments through experiences. The quality of those experiences assures that learners learn in-depth and that their interest increases. Research has shown that out-of-the-school learning environments are influential in the development of students' science skills, in learning various subjects of science by discovering, in the increase in their academic achievement and their attitudes towards science and in enlivening their scientific curiosity, that those environments facilitate learning, that they enable students to gain first-hand experience, and that they contribute to associating real life with what is learnt at school, to making observations, to data collection, and to interpretation skills by making inferences (Balkan Kıyıcı and Atabek Yiğit, 2010; Bozdoğan, 2007; Chin, 2004; Cox-Petersen, 1999; Griffin, 2004; Guisasola, Morentin and Zuza, 2005).

This study aims to develop activities in relation to using out-of-the-school learning environments and to analyse them from the aspect of scientific process skills (SPS). Thus, the basic research problem was formulated as in the following:

Are there any statistically significant differences between scientific process skills scores of experimental group students who were exposed to out-of-the-school learning environments and those of control group students who were taught in classroom settings? 


\section{Method}

This is a quasi-experimental study conducted with 56 fifth graders attending a secondary school in İliç district of Erzincan in the 2014-2015 academic year. The students in the experimental group studied in an orchard in the vicinity of the school by using the technique of learning in stations, with the help of knowledge sheets. The control group students, on the other hand, were taught inside the school during this period. Data were collected from both groups at the end of this period of time by using observation forms requiring observation, data recording, measuring, classification and operational definition skills. A rubric was used in assessing those scientific process skills. The students were evaluated by two science teachers using the rubric, and Pearson's correlation coefficient was calculated, and reliability coefficient was calculated by using Spear-Brown reliability prediction formula since the average for the scores given by the two raters was used (Crocker and Algina, 1986). The rubric scores were analysed by using unrelated (independent) samples t- test. The SPSS 18. 00 Statistical packet for social sciences was employed in the analyses.

\section{Findings}

Independent Groups t-test Results

Table 1. Independent Samples t-test Results for the Experimental and the Control Group

\begin{tabular}{|c|c|c|c|c|c|c|c|}
\hline SPS & Groups & $\mathrm{n}$ & $\bar{X}$ & SD & $\mathrm{df}$ & $\mathrm{t}$ & $\mathrm{p}$ \\
\hline \multirow{2}{*}{$\begin{array}{l}\text { Observation } \\
\text { and model } \\
\text { formation }\end{array}$} & Control & 27 & 1.019 & 0.612 & \multirow{2}{*}{54} & \multirow{2}{*}{-3.414} & \multirow{2}{*}{001} \\
\hline & Experimental & 29 & 1.552 & 0.557 & & & \\
\hline \multirow{2}{*}{$\begin{array}{l}\text { Data } \\
\text { recording }\end{array}$} & Control & 27 & 1.037 & 0.619 & \multirow{2}{*}{54} & \multirow{2}{*}{.717} & \multirow{2}{*}{477} \\
\hline & Experimental & 29 & 1.555 & 0.614 & & & \\
\hline \multirow{2}{*}{$\begin{array}{l}\text { Measurement } \\
\text { and } \\
\text { classification }\end{array}$} & Control & 27 & 0.907 & 0.605 & \multirow[b]{2}{*}{54} & \multirow[b]{2}{*}{-.688} & \multirow[b]{2}{*}{.495} \\
\hline & Experimental & 29 & 1.017 & 0.590 & & & \\
\hline \multirow{2}{*}{$\begin{array}{l}\text { Operational } \\
\text { definition and } \\
\text { prediction }\end{array}$} & Control & 27 & 0.833 & 0.679 & \multirow{2}{*}{54} & \multirow{2}{*}{-2.728} & \multirow{2}{*}{009} \\
\hline & Experimental & 29 & 1.345 & 0.721 & & & \\
\hline
\end{tabular}

According to Table 1, activities implemented in out-of-the-school learning environments have significant effects on observation skills $(\mathrm{t}(54)=-3.414, \mathrm{p}<0.05)$. As is clear from the table, there is a significant difference between the experimental group $(X=1.345)$ and the control group $(X=0.833)$ in favour of the experimental group in terms of operational definition and prediction skills. No significant 
differences were found between the groups in terms of data recording skills $(\mathrm{t}(54)=-$ $.717, \mathrm{p}>0.05)$ and measurement and classification skills $(\mathrm{t}(54)=-.688, \mathrm{p}>0.05)$.

\section{Conclusions and Discussion}

This study, which analysed the effects of out of the school field trip activities on students' SPS in the framework of the science subject of "Let us Learn Living Organisms", calculated the arithmetic averages for the post-test given to the experimental and the control group students. On comparing the averages, it was found that the levels of scientific process skills of the experimental group students who were exposed to activities of out-of-the-school learning environments were higher than those of the control group students.

It was found that the experimental group students' participation in out-ofthe-school activities influenced their observation, data use and model formation skills in positive ways and improved those skills. In parallel to the findings obtained in this study, Balkan Kıyıcı and Atabek Yiğit (2010) found that out-of-the-school environments enabled students to make observations. No significant differences were found between the experimental and the control groups in terms of data recording, and measurement and classification skills. This finding was attributed to the fact that this was a short term study and that the activities were frequently done in the in-class applications in accordance with the curriculum. A review of the literature indicates that long-term and repeated trips should be organised in order for effective learning to occur in out-of-the-school learning environments (Bozdoğan and Yalçın, 2006). Besides, it was also observed that the experimental group students' participation in out-of-the-school activities improved their operational definition and prediction skills. The improvement of these skills in out-of-theschool learning environments was attributed to the fact that individuals were active in the process of reaching knowledge and that they structured the knowledge. Supportive of the findings of this study, Yavuz and Balkan Kiyıc1 (2012) point out that out-of-the-school learning environments make abstract concepts meaningful by making them concrete though one to one interactions.

In conclusions, out-of-the-school field trips to a number of places from botanical gardens to science centres as well as to appropriate fields of nature close to the school can be organised. In this study, a non-agricultural hobby garden was chosen in order to observe and understand the diversity of living organisms through samples of different plants. With the environment prepared, it was assured that students observed and described real samples of plants, and it was also assured that they analysed conceptual knowledge with the help of knowledge sheets. This contributes to them significantly in looking at the samples of living organisms in their vicinity more scientifically and in making sense of nature. This also assures that scientific process skills such as making observations, classifying, measurement, data recording and using, and model formation -which are predicted by the curriculum- are improved. 